${ }^{\circ}$ Entomologica Fennica. 10 June 1999

\title{
Cuticular microstructures of abdominal tergites and sternites of Cloeon sp. (Ephemeroptera; Baetidae) during post-embryonic devel- opment
}

\author{
Susmita Gupta, Abhik Gupta \& V. Benno Meyer-Rochow*
}

Gupta, S., Gupta, A. \& Meyer-Rochow, V.B. 1998: Cuticular microstructures of abdominal tergites and sternites of Cloeon sp. (Ephemeroptera; Baetidae) during post-embryonic development. — Entomol. Fennica 10: 51-59.

\begin{abstract}
The postembryonic changes of the external microstructure of the cuticle on the abdominal tergites and sternites of Cloeon sp. (Ephemeroptera:Baetidae) are described. An inventory of the structures as the aquatic nymph grows and becomes transformed into a terrestrial subimago and then an imago, is provided. It is found that sensillar diversity on nymphal tergites increases with development, but remains unchanged on the sternites. While nymphs and subimago possess various types of sensilla trichoidea, sensilla basiconica are apparent on the imaginal abdomen only. Furthermore, the scaled and spiny cuticle of the nymph becomes relatively smooth in the adult stages. The distinct changes which structure and distribution of the scales as well as marginal spines on the abdominal tergites and sternites of the nymphs undergo during development, must find a reflection in behavioural changes of the larvae. Finally, the taxonomic implications of the observed changes are discussed.
\end{abstract}

Susmita Gupta, Regional Sophisticated Instrumentation Centre, Bijni Complex, North Eastern Hill University, Shillong, Meghalaya, 793003 India. Abhik Gupta, Department of Ecology, Assam University, P.B. No. 63, Silchar, Assam, 788001, India. V. Benno Meyer-Rochow, Department of Biology, University of Oulu, SF90570 Oulu, Finland; e-mailvmr@sun3.oulu.fi

*Corresponding author and present address:

Institute of Arctic Medicine, University of Oulu, Aapistie 1, SF-90220 Oulu, Finland (e-mail:vmr@cc.oulu.fi)

Received 8 March 1998, accepted 3 July 1998

\section{Introduction}

Mayflies represent an important component of the ecology of many boreal as well as high altitude freshwater systems, as their nymphs, being mostly primary consumers, are actively involved in the processing and cycling of nutrients (Cummins
1973; Merritt et al. 1984). They are also unique among the insects in having a subimago - instead of a pupa - following the nymphal stage in their life cycle.

The microstructures on the cuticle, especially that of the nymphal abdominal tergites of many ephemeropterans have been used for defining taxa 
as well as for constructing phylogenetic relationships (Müller-Liebenau 1973, 1983, 1984, 1985; Tsui \& Peters, 1975) and scanning electron micrographs of nymphal spines and setae have accompanied the description of a new genus of Leptophlebiidae (Pescador 1997). Yet, no systematic study is available on the postembryonic development of these structures in the different developmental stages of the nymphs of any mayfly species. Furthermore, practically nothing is known about the changes in the external microstructure of the cuticle as the aquatic nymph is transformed, first to a terrestrial but reproductively immature subimago, and finally to a reproducing imago.

The present paper describes the external microstructure of the abdominal cuticle of different developmental stages of the nymph, and those of the subimago and imago as well, of one species of Cloeon (Ephemeroptera: Baetidae) from Shillong, Meghalaya State, India, by scanning electron microscopy. Besides providing an inventory of cuticular microstructures in this species, which may subsequently be compared with those of other taxa ( $c f$. recently published descriptions of larval sensilla on thorax and abdomen of Saltatoria, Mantodea, Blattaria, Heteroptera, Lepidoptera, and Diptera: Green \& Hartenstein 1997), the findings are of relevance also to nymphal and adult behaviour.

\section{Material and methods}

Nymphs of one species of Cloeon sp. were collected from Ward Lake, a small artificial lake in Shillong $\left(25^{\circ} 34^{\prime} \mathrm{N}\right.$; $\left.91^{\circ} 52^{\prime} \mathrm{E}\right)$, Meghalaya State, India, and sorted into 4 developmental stages on the basis of wingpad development (Clifford 1970). Despite considerable effort, identification to species level was not possible, but this fact must not distract from the goal of the investigation for which the knowledge that throughout the investigation only one species was used was the most critical factor. According to MüllerLiebenau (pers. comm.) the species is different from the common Indian species Cloeon marginalis.

Nymphs were reared in the laboratory to obtain subimagines and imagines. The abdomens of 20 nymphs, subimagines, and imagines ( 10 each for tergites and sternites), were fixed for $2 \mathrm{~h}$ in $2-5 \%$ glutaraldehyde and postfixed for $2 \mathrm{~h}$ in $2 \%$ osmium tetroxide, both fixatives buffered with $0.1 \mathrm{M}$ cacodylate to a $\mathrm{pH}$ of 7.2 . These were dehydrated in a graded series of acetone, dried in a critical point dryer, mounted on aluminium stubs, and coated with gold with the aid of a fine coat ion-sputter JFC 1100 . The specimens were examined and photographed in a JSM 35 CF scanning electron microscope. Sensillar dimensions were obtained from photographs and averages with standard deviations are based on 20 measurements for each type of sensilla. To establish the porosity of sensilla, the entire subimago and imago were immersed for 2 days in $70 \%$ ethanol containing $0.1 \%$ silver nitrate and examined in a Leitz-Ortholux phase contrast microscope (Nayak \& Singh 1983).

\section{Results}

\subsection{Cuticular microstructures on abdominal tergites}

Data on the lengths, socket diameters, and other morphometric details of the different cuticular microstructures in the various nymphal stages are presented in Table 1.

\subsubsection{Stage 1 nymph}

The surface of every tergal segment is beset with numerous scale-like structures with spiny margins (Fig. 1). Socketed sensory hairs, designated as sensilla trichoidea type 1, are strewn among the scales (Fig. 1). The lateral regions and the posterior extremities of tergites are provided with several sensilla campaniformia in the form of roughly circular to oblong cuticular domes (Fig. 2). Spines on the hind margins of tergal segments are very poorly developed (Fig. 2).

\subsubsection{Stage 2 nymph}

Some of the spiny scales of stage 1 apparently develop into tongue-shaped cuticular plates with serrated margins (Fig. 3). This change is more pronounced on the lateral regions of the tergites. Sensilla trichoidea type 1 and sensilla campaniformia, similar to those in stage 1 , are also present. Additionally, sensilla basiconica, arranged in 3 clusters, one in the anteromedial region, and one each in the anterolateral regions of the tergites, are noticed also in this stage. Each cluster has 810 short, socketed sensilla with curved and tapered, but somewhat blunt, tips (Fig. 4). Spines on the hind margin are distinctly developed in 
Table 1. Morphometric data of the cuticular structures on the abdominal tergites and sternites of Cloeon sp.

\begin{tabular}{|c|c|c|c|}
\hline Cuticular structure & Development stage & Length in $\mu \mathrm{m}$ ( \pm s.d.) & Diam./width in $\mu \mathrm{m}$ ( \pm s.d.) \\
\hline
\end{tabular}

Nymph

1. Sensilla trichoidea

$\begin{array}{lccc}\text { (i) type 1 } & 1-4 & 17.1 . \pm 7.8 & 1.7 . \pm 0,3 \mathrm{a} \\ \text { (ii) type 2 } & 2-4 & 30.1 \pm 4.2 & 1.5 \pm 0.3 \mathrm{a} \\ \text { S. basiconica } & 2-4 & 3.9 \pm 0.8 & 1.3 \pm \pm 0.3 \mathrm{a} \\ \text { S. campaniformia } & & \text { n.a. } & 4.8 \pm 0.5 \mathrm{~b} \\ \text { (i) tergites } & 1-4 & \text { n.a. } & 3.6 \pm 0.5 \mathrm{~b} \\ \text { (ii) sternites } & 1-4 & 4.0 \pm 0.5 & 5.2 \pm 0.6 \mathrm{c} \\ \text { Tongue-shaped plates } & 2-4 & & \\ \text { Hind margins spines } & & 2.5 \pm 0.8 & 0.41 \pm 0.16 \mathrm{c} \\ \text { (i) tergites } & 1 & 9.2 \pm 3.9 & 3.8 \pm 1.6 \mathrm{c} \\ & 2 & 21.1 \pm 4.8 & 7.2 \pm 2.8 \mathrm{c} \\ & 3-4 & 1.9 \pm 0.6 & 2.4 \pm 0.8 \mathrm{c} \\ \text { (ii) sternites } & 1 & 9.0 \pm 3.7 & 5.3 \pm 1.7 \\ & 2 & 15.2 \pm 4.4 & 5.8 \pm 1.5 \mathrm{c}\end{array}$

Subimago

1. Hair sensilla

$5.7 \pm 1.4$

$1.04 \pm 0.14 \mathrm{c}$

2. S. trichoidea

$14.3 \pm 2.1$

$3.8 \pm 0.5 \mathrm{a}$

3. S. with bulbose base

female

$8.9 \pm 2.5$

$3.9 \pm 0.4 \mathrm{c}$

Adut

1. S. trichoidea

$7.6 \pm 0.8$

$0.87 \pm 0.1 \mathrm{a}$

2. S. basiconica

$6.1 \pm 1.0$

$3.4 \pm 0.7 a$

3. Spinules on sternites

$3.7 \pm 0.5$

$1.5 \pm 0.2 \mathrm{c}$

$\mathbf{a}=$ socket diameter $\mathbf{b}$ = diameter $\mathbf{c}=$ basal width; n.a. = not applicable

segments 7-9, and comprise shorter spines interspersed among relatively longer ones (Fig. 5).

\subsubsection{Stage 3 nymph}

The "tongue-shaped" plates that were mainly confined to the lateral regions of the tergites in the stage 2 nymph, are uniformly distributed throughout their surfaces in this stage. In addition to sensilla trichoidea type I and sensilla basiconica, sensilla trichoidea type 2 , having a narrow base followed by a relatively broad and flattened area, are also present. These sensilla lack well-defined sockets at their bases (Fig. 6). Sensilla campaniformia, as in the previous stages, are also found. Spine formation on the hind margins of tergites commences from segment 2 (Fig. 7), although these are well-developed in segments 5-9.

\subsubsection{Stage 4 nymph}

Cuticular microstructures on the tergite surface are similar to those found in stage 3 . Hind margin spines are, however, well-developed from segment 2 (Fig. 8).

\subsubsection{Subimago}

The subimaginal abdominal tergite surface is markedly different from that of the nymphs. All the tergites are covered with unsocketed hairs, 

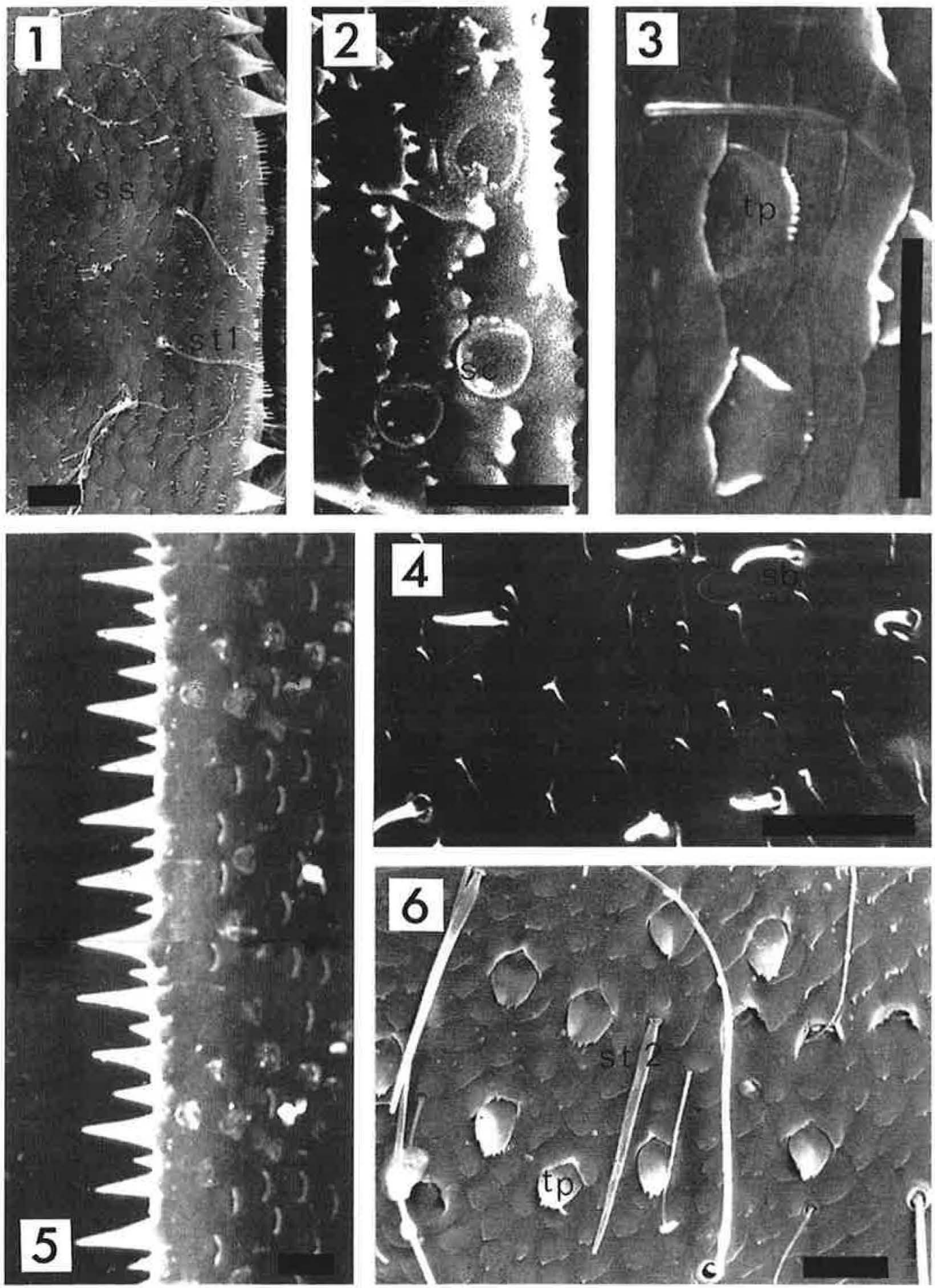

Fig.s 1-6. 1. Surface of abdominal tergite 9, stage 1 nymph; ss = spiny scales; st 1 = sensilla trichoidea type 1 . Bar: $10 \mu \mathrm{m} ; 2$. Hind margin of tergite 7 , stage 1 nymph; $\mathrm{sc}=$ sensilla campaniformia. Bar: $10 \mu \mathrm{m} ; 3$. Surface of tergite 5 , stage 2 nymph; $t p=$ tongue-shaped plate. Bar: $10 \mu \mathrm{m} ; 4$. Lateral region, tergite 5 , stage 2 nymph; sb = sensilla basiconica. Bar: $10 \mu \mathrm{m} ; 5$. Hind margin of tergum 7, stage 2 nymph. Bar: $10 \mu \mathrm{m} ; 6$. Surface of tergite 6 , stage 3 nymph; st2 = sensilla trichoidea type 2 ; tp = tongue-shaped plate. Bar: $10 \mu \mathrm{m}$. 

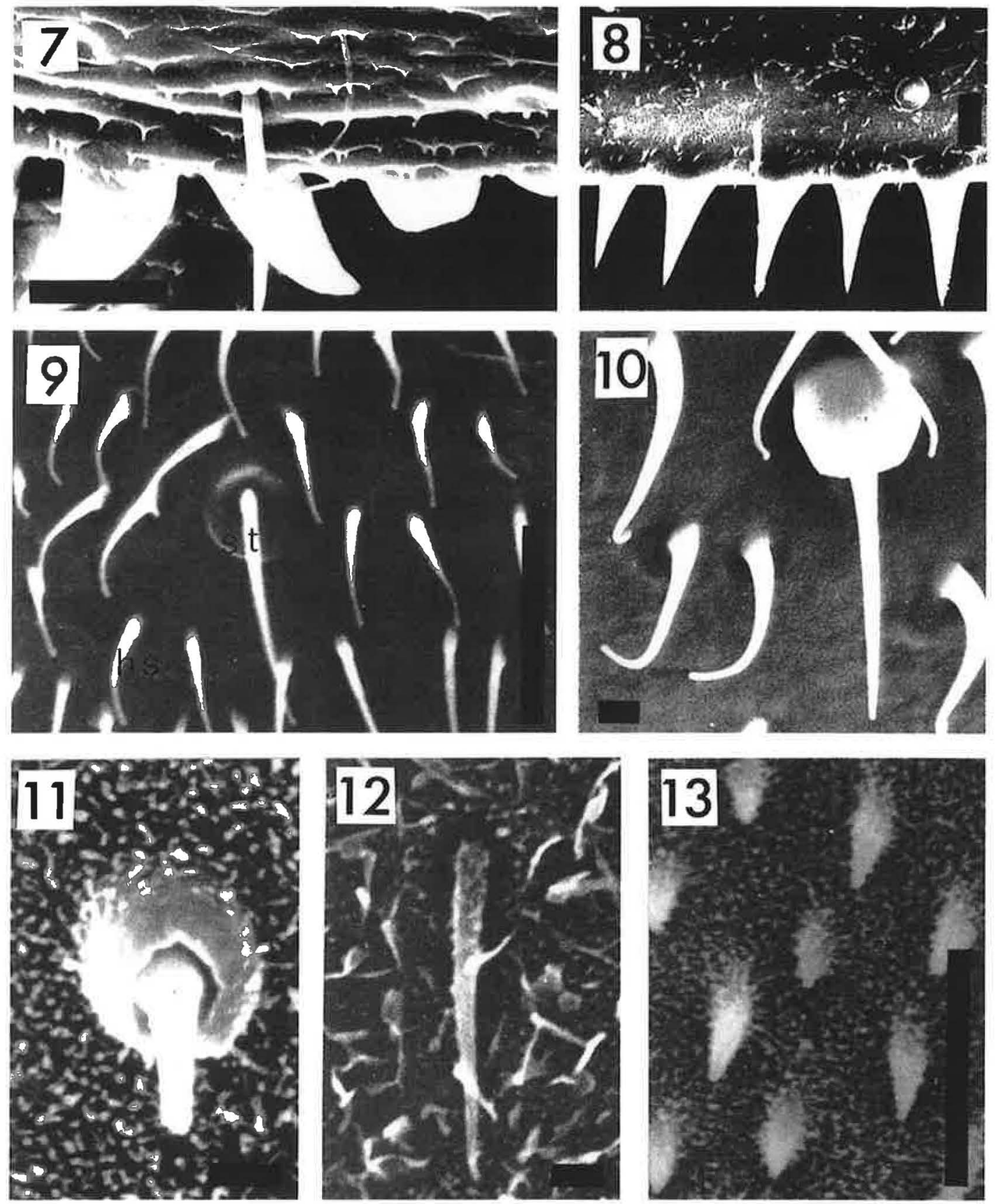

Figs. 7-13. 1. Hind margin of tergite 2, stage 3 nymph. Bar: $10 \mu \mathrm{m} ; 8$. Hind margin of tergite 2, stage 4 nymph. Bar: $10 \mu \mathrm{m} ; 9$. Tergite surface, subimago; hs = hair sensilla; st = sensilla trichoidea. Bar: $10 \mu \mathrm{m} ; 10$. Tergite surface, female subimago; bs = sensilla with bulbous base. Bar: $1 \mu \mathrm{m} ; 11$. Sensilla basiconica on tergite of imago. Bar: $1 \mu \mathrm{m}$; 12. Sensilla trichoidea on tergite of imago. Bar: $1 \mu \mathrm{m} ; 13$. Spines on sternite of imago. Bar: $10 \mu \mathrm{m}$. 
largely oriented along the long axis of the body, their tips facing posteriorly. They gradually taper from their bases, and have curved and slightly bulbous tips (Fig. 9). Scattered among these hairs are a few sensilla trichoidea emerging from circular sockets (Fig. 9) . Furthermore, only the female subimago possesses clusters of sensilla in the anterolateral and anteromedial regions of its tergites. Individual clusters have 10-11 sensilla, each with a prominent bulbous unsocketed base with a spine-like projection (Fig. 10). The hind margin of the subimaginal tergites, in contrast to the nymphs, are devoid of any spine or projection.

\subsubsection{Imago}

The surface of imaginal tergites shows extremely minute cuticular foldings. The dense hairs of the subimago are absent. However, each imaginal tergite has 3 distinct clusters of sensilla basiconica in the anterior region, each cluster having 10-11 basiconic pegs. The location of these clusters as well as the orientation of their constituent sensilla appear to be fairly constant. While the sensory pegs in the central cluster point downward and backward, those in the lateral clusters point laterally. These pegs emerge from circular sockets, and taper gradually (Fig. 11). Furthermore, sensilla trichoidea that emerge from circular punctures in the cuticle are sparsely and irregularly distributed on the surface of all tergal segments (Fig. 12). The cuticular foldings mentioned earlier are more pronounced around the bases of these sensilla. The hind margins of the tergites are smooth, as in the subimago.

Morphometric data on the cuticular structures of the subimaginal and imaginal tergites are provided in Table 1.

\subsection{Cuticular microstructures on the ab- dominal sternit}

\subsubsection{Nymph}

As in the case of tergites, the spiny scales in the stage 1 nymph develop into "tongue-shaped" plates with serrated margins in stage 2 and 3 nymphs. However, unlike the tergites, the sternites possess sensilla trichoidea types 1 and 2, as well as the basiconic pegs in stage 1 itself. Sensilla campaniformia, somewhat smaller than those found on the tergites (Table 1) are also present. The spines on the hind margin are present from the 8 th segment onwards in stage 1 , from the 7 th in stage 2 , from the 6 th in stage 3 , and from the 3rd in stage 4 nymphs.

\subsubsection{Subimago}

These are similar to the tergites, barring the fact that sensilla found only on the female tergites are absent from the sternites.

\subsubsection{Imago}

Sensilla similar to those on the tergites can be seen, although the sternites are beset with numerous small spines that are are prominent in their posterolateral regions (Fig. 13). Data on their lengths and widths are provided in Table 1.

\subsection{Species Characteristics}

Some taxonomically important characters such as male genitalia, female forewing, mature nymphal mouthparts, etc. are shown in the line drawings of Fig. 14.

\section{Discussion}

Obviously, those structures on the abdominal tergites and sternites of nymphs and adults of Cloeon sp. identified as 'sensory' in nature have a role to play in the aquatic phase of the species. Their exact function(s), however, cannot be ascertained until results are available on their innervation and other ultrastructural attributes. Nevertheless, extrapolations from SEM and TEMbased studies on insect sensilla generally enable us to suggest some of their possible functions. 

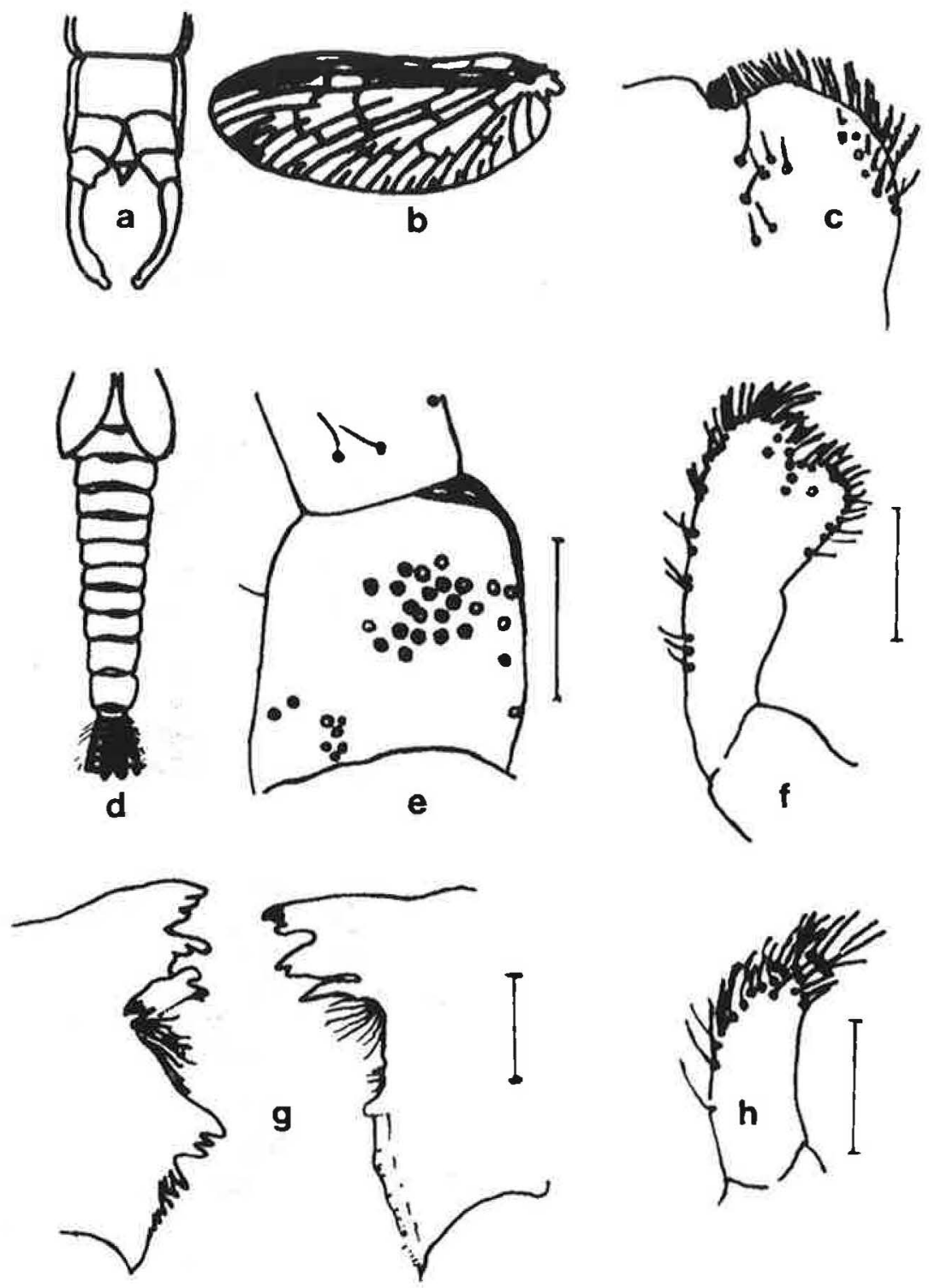

Fig. 14. Taxonomically important characteristics of the Cloeon sp. used in this investigation. - (a) Genitalia of male imago. - (b) forewing of female imago. - (c) labrum of mature nymph. - (d) nymphal exuvium. - (e) basal antennal segment of mature nymph. - ( $\mathrm{f}$ ) tip of labial palp of mature nymph. - (g) mandibles of mature nymph. (h) tip of maxillary palp of mature nymph. The scale is $0.1 \mathrm{~mm}$.

Sensilla trichoidea type 1, with their slender, pliable setae, and sockets that allow movement in all directions, are likely to be mechano- or contact chemosensilla (Frazier 1985, Crouau \& Crouau-Roy 1991) and may also be used for cleaning detrital and other debris from the abdominal surface as well (Honegger 1977, Zack \& Bacon 1981). Sensilla trichoidea type 2 , in the absence of sockets, may only serve simple tactile functions (Schmidt \& Smith 1987). The basiconic pegs, on the other hand, are likely to be chemoreceptors. The nymphs of all stages have sensilla campaniformia in the lateral regions and along the posterior margins of their tergites and sternites. The proprioceptive functions of these sensilla are well known (Zill \& Moran 1981a, 1981b; Spinola 
\& Chapman 1975, Schmidt \& Smith 1987).

The present study reveals that the sensillar diversity on the tergites increases from stage 1 to stage 3 and 4 nymphs, which suggests that the tergites play a progressively greater role in monitoring the environment as nymphal development proceeds. In contrast, all the 3 types of sensilla are present on the stage 1 sternites, which, thus, are likely to start performing diverse sensory functions early in nymphal life. In damselfly larvae Richardson and Anholt (1995) observed significant changes in 11 behavioural patterns as the larvae grew older: some (e.g. abdomen-raise, sidecrawl) decreased while others (e.g. $180^{\circ}$-turns, feeding, abdomen wave) increased. On the basis of our findings, one would to expect to find similar (but not necessarily the same) behavioural changes in maturing mayfly nymphs.

The spiny plates on the nymphal abdomen, along with the spines on the hind margins of tergites, have been used for delimiting taxa (Müller-Liebenau 1973, 1983, 1984, 1985) and featured in the description of the new leptophlebiid genus Gonserrelus (Pescador 1997). However, nothing precise is known about their functional significance. In the marine isopod Glyptonotus antarcticus microscales on the cuticle have been shown to be effective in discouraging colonization by foraminiferans and other epizoons (MeyerRochow 1980) and Peckarsky (1987) observed that an abdomen-bending "scorpion"-like posture by Ephemerella nymphs resulted in the cerci and the flexed abdominal spines acting as a defence mechanism against predatory stoneflies. The spiny scales of Cloeon could, therefore, serve to discourage bacterial, fungal, and protozoan infestations, and together with the marginal spines may facilitate defence against predators as well.

The spiny scales or plates, however, do not remain constant throughout the larval life, but exhibit certain changes during nymphal development. While they are in the form of somewhat indistinct folds of the cuticle with spiny edges in stage 1, they get transformed into distinct "tongueshaped" spiny plates in the lateral regions of the abdomen in stage 2 , and subsequently spread to the other areas of the abdomen in stages 3 and 4. Similarly, the marginal. spines first develop on the distal abdominal segments, and as development proceeds, they gradually appear on the proximal segments as well. This observation implies that only the mature 4th-stage nymph has to he used for taxonomic descriptions and comparisons, as nymphs belonging to the same species (but to different developmental stages), will show differences in the anatomical features of the surface and hind margins of their tergites, leading to possible mistakes in identifications.

The nymphal scales disappear in the subimago, whose entire body, including the abdomen, is covered with a dense coating of unsocketed hairs. Besides serving tactile functions, these hairs probably act as a hydrofuge device to prevent drowning of the subimago as it emerges on the water surface, and subsequently to provide heat insulation as terrestrial existence commences. Similar roles for cuticular hairs in general. have been suggested by Neville (1975). The socketed trichoid sensilla found on the subimaginal abdomen may serve either a mechano- or a chemoreceptive function, while the other type with a bulbous base is found only in the female, and is an expression of sexual dimorphism. Staining with silver nitrate reveals that the base is perforated, thereby indicating its chemosensory nature.

The numerous hairs of the subimago are discarded during imaginal moult, leaving the surface smooth. Lameere (1917) suggested that this transformation facilitated flying by reducing the body weight, but it also diminishes friction against air. It has been shown that mayflies that do not shed their subimaginal skin do not have sustained mating flights (Needham et al. 1935). The imaginal tergites and sternites, however, retain sensilla trichoidea, likely to be mechanoreceptors, and sensilla basiconica that may be involved in olfactory recognition of mates during swarming. It is known that mayfly eyes, including the highly developed dorsal turbinate eyes (which are present in the male imago, but not sub-imago: MeyerRochow 1971) of the Baetidae, to which Cloeon sp. belongs, are not designed for distance perception of small flying objects (Wehner 1981, Wehner \& Srinivasan 1984). This drawback was overcome by the evolution of swarming, which facilitated detection of females by males as the former enter the swarm and can be recognized at a closer distance (Fischer 1991). Critical for recognition by sight, however, is that environmental light conditions permit the visual signals to be registered and 
understood. Whether in the absence of light sexual recognition takes place or blinded individuals are able to mate is unknown, but it does seem feasible that the basiconic sensilla could be part of a 'back-up system' aiding the two sexes to detect and locate each other in conditions of poor visibility. Following pair formation, the minute spines on the sternites most probably enable better grip during mating.

Acknowledgements. The authors wish to thank Prof. Dr. D.T. Khathing, Head, Regional Sophisticated Instrumentation Centre, North-Eastern Hill University (NEHU), Shillong, for his encouragement and help and V.B.M-R. is grateful to NEHU for the financial and logistic support received during his sabbatical stay of 2 months in Shillong.

\section{References}

Clifford, H. F. 1970: Analysis of a northern mayfly (Ephemer-optera) population, with special references to allometry of size. - Can. J. Zool. 48:305-316.

Crouau, Y. \& Crouau-Roy, B. 1991: Antennal sensory organs of a troglobitic coleoptera, Speonomus hydrophilus Jeannel, (Catopidae): an ultrastructural study by chemical fixation and cryofixation. - Int. J. Insect Morphol. Embryol. 20:169-184.

Cummins, K. W. 1973: Trophic relations of aquatic insects. - Annu. Rev. Entomol. 18:183-206.

Fischer, C. 1991: Evolution des Schwarmfluges and Flugverhalten der Ephemeropteren. - Dissertation: Universität Erlangen, Nürnberg, Germany. 171 pp.

Frazier, J. L. 1985: Nervous system; sensory system. - In: Blum, M. S. (ed.) Fundamentals of Insect Physiology: 287-356. John Wiley \& Sons, New York. 400 pp.

Green, P. \& Hartenstein, V. 1997: Structure and spatial pattern of the sensilla of the body segments of insect larvae. — Micr. Res. Tech. 39:470-478.

Honegger, H. W. 1977: Interommatidial hair receptor axons extending into the ventral nerve cord in the cricket Gryllus campestris. - J. Comp. Physiol. 130:49-62.

Lameere, A.1917: Etude sur l'évolution des éphémères. Bull. Soc. Zool. France 42:41-59.

Merritt, R. W., Cummins, K. W. \& Burton, T M. 1984: The role of aquatic insects in the processing and cycling of nutrients. - In: Resh, V.H. \& Rosenberg, D.M. (eds.), The ecology of aquatic insects: 134-163. Praeger, New York 625 pp.

Meyer-Rochow, V .B. 1971: Fixierung von Insektenaugen mit Hilfe eines Netzmittels - das Dorsalauge von Atalophlebia costalis. - Mikrokosmos 60:348-352.

Meyer-Rochow, V.B. 1980: Cuticular surface structures in Glyptonotus antarcticus - a marine isopod from the Ross Sea (Antarctica). — Zoomorphol. 94:209-216.

Müller-Liebenau, I. 1973: Morphological characters used in revising the European species of the genus Baetis Leach. — Proc. 1st. Int. Conf. Ephemeroptera (Leiden): 180-
192.

Müller-Liebenau, I. 1983: The new species of the genus Centroptella Braasch and Soldan, 1980, from Sri Lanka (Insecta: Ephemeroptera). - Arch. Hydrobiol. 97:486500.

Müller-Liebenau, I. 1984: New genera and species of the family Baetidae from West Malaysia (River Gombak) (Insecta: Ephemeroptera). - Spixiana 7:253-284.

Müller-Liebenau, I. 1985: Baetidae from Taiwan with remarks on Baetiella Ueno, 1931 (Insecta: Ephemeroptera). Arch. Hydrobiol. 104:93-110.

Nayak, S.V. \& Singh, R.N. 1983: Sensilla on the tarsal segments and mouthparts of adult Drosophila melanogaster Meigen (Dipetra: Drosophilidae). - Int. J. Insect Morphol. Embryol. 12:273-291.

Needham, J. G., Traver, J. R. \& Hsu, Y. C. 1935: The biology of mayflies with a systematic account of North American species. - Comstock Press, Ithaca. 759 pp.

Neville, A. C. 1975: Biology of arthropod cuticle. - Springer, Berlin.

Peckarsky, B. L. 1987: Mayfly cerci as defense against stonefly predation: deflection and detection. - Oikos 48:161-170.

Pescador, M. L. 1997: Gonserellus: a new genus of Leptophlebiidae (Ephemeroptera) from southern South America. - Aquatic Insects: 237-242.

Richardson, J. M. \& Anholt, B. R. 1995: Ontogenetic behaviour changes in larvac of the damselfly Ischnura verticalis (Odonata: Coenagrionidae). — Ethology 101:308-334.

Schmidt, J. M. \& Smith, J. J. B. 1987: The external sensory morphology of the legs and hairplate system of female Trichogramma minutum Riley (Hymenoptera: Trichogrammatidae). - Proc. Roy. Soc. Lond. (B) 232:323-366.

Spinola, S. M. \& Chapman, K. M. 1975: Proprioceptive indentation of campaniform sensilla of cockroach legs. J. Comp. Physiol. 95:257-272.

Tsui, P. T. P. \& Peters, W. L. 1975: The comparative morphology and phylogeny of certain Gondwanian Leptophlebiidae based on the thorax, tentorium, and abdominal terga (Ephemeroptera). - Trans. Am. Entomol. Soc. 101:505-595.

Wehner, R. 1981: Spatial vision in arthropods. In: Autrum, H. (ed.), Handbook of sensory physiology Vol. 7, Pt. 6c:287-616. - Springer, Berlin.

Wehner, R. \& Srinivasan, M. V. 1984: The world as the insect sees it. - In: Lewis, T. (ed.), Insect communication: 29-47. 12th Symp. Roy. Entomol. Soc. London: Academic Press, New York.

Zack, S. \& Bacon, J. 1981: Interommatidial sensilla of the preying mantids: their central neural projections and role in head-cleaning behaviour. - J. Neurobiol. 12:55-65.

Zill, S.N. \& Moran, D.T. 1981a: The exoskeleton and insect proprioception. I. Responses of tibial campaniform sensilla to external and muscle-generated forces in the American cockroach, Periplaneta americana. - J. Exp. Biol. 91:1-24.

Zill, S. N. \& Moran, D. T. 1981b: The exoskeleton and insect proprioception. III. Activity of tibial campaniform sensilla during walking in the American cockroach, Periplaneta americana. - J. Exp. Biol. 94:57-75. 